\title{
CERVICAL CANCER SCREENING USING ACETIC ACID AMONG HIGH RISK WOMEN AND PLAN OF NURSING ACTION
}

\author{
Amany Abdo Hussien ${ }^{(1)}$, Sanaa Ali Nour ${ }^{(2)}$, Mohamed Nagib Azaam ${ }^{(3)}$, \\ Hend Salah El-Din ${ }^{(4)}$ \& Amany Hamed Gad ${ }^{(5)}$ \\ ${ }^{(1)}$ Assistant lecturer in Obstetrics and Gynecological Nursing, Faculty of Nursing, Zagazig \\ University. ${ }^{(2)}$ Professor of Obstetrics and Gynecological nursing, Faculty of Nursing, Zagazig \\ University. ${ }^{(3)}$ Professor of Obstetrics and Gynecology, Faculty of Medicine, Zagazig University \\ (4) Professor of Obstetrics and Gynecological nursing, Faculty of Nursing, Zagazig University. ${ }^{(5)}$ \\ Assist. Professor of Obstetrics and Gynecological nursing, Faculty of Nursing, Zagazig University.
} Email:mena21053@yahoo.com Tel: 01062492471

\begin{abstract}
:
Background: Screening for cervical cancer using visual inspection with acetic acid (VIA) has been advocated by WHO as a suitable, low cost and feasible alternative modality for control of cervical cancer in low resource setting. The aim of the study was to assess cervical cancer screening for high risk women using acetic acid and implement the plan of nursing action. A cross-sectional design was carried out in the Gynecological OPD at Zagazig University Hospitals. A purposive sample of 100 females was required to estimate sensitivity and specificity of acetic acid in identifying pre malignant epithelial cell changes of the cervix. The tools used for data collection were; a structured interview sheet, clinical assessment sheet and the plan for nursing action. The results revealed that, women at risk for cervical cancer were more likely to be $>30$ years and more, their age of marriage was <20 years, had positive family history of cancer. They were also multipara, had repeated cervical laceration, exposed to STIs especially chlamydia and menorrhagia was present in $29.0 \%$ of them. Meanwhile post-coital bleeding was reported by $19.0 \%$ of the participants. Positive result for premalignant cervical lesion was $26.0 \%$ for VIA. Sensitivity and specificity of VIA were found to be $100 \%$ and $89.16 \%$ respectively. The accuracy of VIA was $91.0 \%$ which means that VIA test was more accurate. It can be concluded that VIA can effectively identify more cases of cervical intraepithelial neoplasia. It has been proven to achieve high sensitivity with an acceptable specificity. VIA test offers hope for universal screening as an alternate method for low resource setting. It is recommended that; VIA should be actively advocated to improve detection rate of cervical lesions so that it should be performed in all the women attending outpatient gynecological clinics.
\end{abstract}

Keywords: precancerous lesion of cervical cancer, screening using VIA test.

\section{Introduction:}

Cervical cancer is the fourth most common cancer-affecting women worldwide, after breast, colorectal, and lung cancers. It is also the fourth most common cause of cancer death in women worldwide $^{(1)}$. In Egypt 866 new cervical cancer cases are diagnosed annually, 373 die from the disease and ranks as the 13th cause of female cancer ${ }^{(2)}$. Human papillomavirus is an important cause of $99.0 \%$ of all cervical cancers while other risk factors include: sexual intercourse at younger ages, smoking, immune deficiency, multiparty, herpes simplex virus type-2 infection, familial history of cervical cancer, history of genital wart infection and consumption of oral contraceptives for long period ${ }^{(3)}$. 
Cervical cancer has a long pre-invasive period, so it is preventable by various screening strategies. Widespread screening of women for precancerous lesions and early detection can lead to a reduction in cervical cancer incidence and mortality especially among women of reproductive age. Cervical cancer screening is the systematic application of a test to identify cervical abnormalities in an asymptomatic population such as Pap test, liquid-based cytology, HPV DNA testing and visual inspection approaches. Pap test and liquidbased cytology have been effective in diminishing the incidence and mortality rates of cervical cancer in developed countries but not in developing countries due to many challenges and difficulties that have led to the investigation of alternative tests with lower technology such as; the use of VIA in detection of cervical neoplasia ${ }^{(4)}$.

Visual inspection with acetic acid (VIA) has been more widely investigated for its performance in detecting cervical neoplasia. It involves naked eye examination of the 3-5\% acetic acidswabbed uterine cervix without any magnification. After 30-90 seconds, a transient reaction occurs due to osmotic dehydration of dysplastic cells, which accentuate the optically dense chromatin to aceto white areas. It can be done by nurses and other paramedical health workers ${ }^{(5)}$. The most common form of reporting the findings involves negative and positive categories depending upon the absence or presence of acetowhite lesions and clinical signs of invasive cancer. A positive result is based on the detection of well-defined, densely opaque acetowhite lesions in the transformation zone closer to the squamocolumnar junction. While, the negative result included one or more of the following: no acetowhite lesions, faint ill-defined translucent acetowhite lesions, endocervical polyps, nabothian cysts, dot- like acetowhite lesions, acetowhite lesions far away Discrimination from the transformation zone ${ }^{(6)}$. VIA is a simple and inexpensive technology test that does not require a laboratory infrastructure. Consumables required are cheap and universally available. It gives immediate results; enable further investigation or treatment to be performed in the same session. This avoids recall of women for procedure, resulting in logistic advantages, better compliance and cost savings ${ }^{(7)}$. Maternity nurses play a central role in health promotion, prevention, treatment and rehabilitation. They need to be able to educate women about why changes occur, how often screening is recommended and how sampling will be obtained. Therefore, they should understand and stay abreast of the latest cervical cancer screening guidelines, and reinforce the need of screening for all women ${ }^{(8)}$.

Significance of the study: Cervical Cancer continues to be the most common cause of death among middle-aged women in many developing countries due to diagnosis of disease at advanced stages so that early diagnosis of cervical cancer is known to be vital not just in the treatment of the disease but also in determining prognosis. Unfortunately in Egypt and Arabic countries, women currently face a significant risk of high mortality rate due to the delay in diagnosis till the higher tumor stage ${ }^{(9)}$. There are few studies about this problem in Zagazig, for this reason, it is important to conduct this study to evaluate the effectiveness of VIA in preliminary screening of cervical and its precancerous lesions aiming at prevention and early detection.

Aim of the study: was to assess cervical cancer screening for high risk women using acetic acid and implement the plan of nursing action.

Research hypotheses: visual inspection of the cervix after application of acetic acid 5\% is an effective method in early 
CERVICAL CANCER SCREENING USING ACETIC etc...

detection of cervical precancerous
changes.

Research design: A cross-sectional and prospective design was carried out in this study.

Setting: The study was conducted in the Gynecology Outpatient Department (OPD) at Zagazig University Hospitals.

Subjects: A purposive sample of 100 females was required to estimate sensitivity and specificity of acetic acid in identifying pre malignant epithelial cell changes of the cervix among suspected females.

\section{Inclusion criteria:}

The study sample was collected when woman was fulfilled one of the following criteria:

1. Woman aged 20-50 years and attended the gynecological OPD of Zagazig University Hospitals complaining from post coital bleeding, inter-menstrual bleeding, pain and discomfort during sexual intercourse and foul smelling heavy vaginal discharge

2. Multiparous women who were married $<20$ years of age.

3. Women who had several marriage.

4. Women with positive family history of cancer.

5. Those that had long-term use of oral contraceptives.

Tools of data collection:

Tool I: A structured Interview Sheet: was developed to collect data about: (A)Socio-demographic characteristics as: age, occupation \& education level.

(B)Reproductive and sexual history as: age of first sexual intercourse, parity and age at first birth. A detailed medical, family and gynecological history were also obtained.

Tool II: Clinical Assessment Sheet: was developed to collect data about the following:

A- Symptoms as: excessive vaginal discharge, itching in the external anogenitalia, ulcers in the external anogenitalia, lower abdominal pain, pain during sexual intercourse, bleeding after intercourse or intermenstrual and low back ache.

B-Signs: the vulva was examined by for any warts, ulcer and abnormal discharge. C- Investigation for precancerous lesion with VIA.

Tool III: The Plan for nursing action.
Administrative
and
ethical
considerations:

An official permission was granted to the responsible authorities of the study setting to obtain their permission for data collection. Approval of the Ethics Committee of Scientific Research in Faculty of Nursing was obtained. All ethical issues were taken into consideration during all phases of the study. The inclusion in the study was totally voluntary. The aim, procedure, risks and benefits of the study were explained to every woman before participation and an oral consent was obtained. Women can withdraw at any stage of the research without being penalized; also they assured that the information obtained would be confidential and used for research purpose only.

Pilot study: was carried out on 10 women who were not included in the total sample. The pilot was conducted to test the tools for applicability and feasibility. Based on the results of the pilot study, the necessary modifications were done, and the finalized form was developed.

Field study: Collection of data covered a period of 12 months "from the first of August 2016 to the end of July 2017". The researcher attended Gynecological OPD at Zagazig University Hospitals every day from 9 a.m. to 12 p.m. The researcher introduced herself to women and explained to her the objectives of the study. An oral informed consent was obtained; woman's socio-demographic, 
reproductive and sexual history was collected and recorded. Each interview took about 5-10 minutes.

Concerning the clinical assessment and screening of the woman, the researcher was trained beforehand and supervised by the medical supervisor on the proper way of patient's examination, screening and detection of early precancerous lesion.

(1) The researcher started by assembling the following equipment and supplies for the procedure:

Soap and water for washing hands, a bright light source, a sterile Cusco's speculum, disposable gloves, cotton swabs, dilute acetic acid solution (5\%) freshly prepared, cidex for decontaminating instruments and bags for contaminated disposable supplies.

(2)Preparations of $5 \%$ dilute acetic acid: by adding $5 \mathrm{ml}$ of glacial acetic acid into $95 \mathrm{ml}$ of distilled water. Unused $5 \%$ acetic acid should be discarded at the end of the day.

(3) Screening pathway: selected woman was first counseled about the procedure then assisted to lie on the examining table in the dorsal recumbent position. The procedure was carried out by the researcher with the assistance of the on duty physician. Under complete aseptic precautions, external genitalia and vagina were disinfected with antiseptic solution. Light was adjusted in order to get the best view of cervix. Before the screening procedure, a non-lubricated sterile Cusco's speculum was gently introduced in the vagina. The color, amount and smell of cervical discharge were noted. Abnormalities in the cervix should be noted and recorded such as; cervical polyp, nabothian follicles and cervicitis. The cervix was painted with $5 \%$ freshly prepared acetic acid solution using a sterile cotton swab. One minute after application of acetic acid, the cervix was examined for development of any acetowhite area near the squamocolumnar junction. The intensity of aceto-whiteness, borders and location of acetowhite area were noted. After the test, findings were recorded as negative or positive VIA.

(4) Reporting of test outcome

- Positive test: Visualization of the dense acetowhite lesion with sharp margins located in the transformation zone; close to squamocoloumner junction (SCJ).

- Negative test: If no acetowhite lesions were observed on the cervix, polyps protruding from cervix, bluish white in color, nabothian cysts which appear as button like areas as whitish area or pimples and dot like areas present in the endocervix.

\section{(5) Plan for nursing action and referral} protocol:

Women who had negative results were advised for follow-up after two years for rescreening and counseling. Women who suffered from any gynecological problems as cervicitis, cervical polyp, cervical ectropion or vaginitis were obtained nursing instruction and were assisted to seek medical advice. The proper diagnosis was confirmed by the on duty physician and further treatment was given to the patient. While those who tested positive on VIA screening were be referred for cervical biopsy for confirmation, and then referred for staging and treatment.

Statistical design: By using SPSS for windows version 20.0. Data were tested for normality of distribution. Continuous data were expressed in mean \pm SD. Categorical data were expressed in number and percentage. The comparisons were determined using Student's $t$ test for variables with continuous data and Chisquare test for variables with categorical 
CERVICAL CANCER SCREENING USING ACETIC etc ...

data. OR and $95 \%$ CI were calculated the associations between risk factors and the screening method. Sensitivity, specificity, positive predictive value, negative predictive value and accuracy of the VIA test were calculated. Statistical significance was set at $\mathrm{p}<0.05$.

Limitations of the study: It was not easy to counsel woman about her possibility of exposure to cancer cervix that is why many cases were dropped after the VIA screening and refused further screening or treatment because of the many misconceptions surrounding this problem.

\section{Results:}

Table 1 shows that, the maximum number of women was in the age group of 30 years and more $(83.0 \%)$ with a mean age of 38.9 \pm 7.3 years. In terms of education $30.0 \%$ had secondary level of education and $61.0 \%$ were housewives. More than two thirds $(69.0 \%)$ of them were coming from rural areas and $30.0 \%$ were passive smoker with a mean duration of exposure $14.4 \pm 7.3$ years.

Table 2 shows that about two thirds of women $(59.0 \%)$ were married at the age of 20-25 years with a mean of $21.5 \pm 2.9$ years.

Table 3 shows that $13.0 \%$ of women were exposed to STD; chlamydia was the most common, followed by equal percentages of genital herpes and genital warts $(53.8 \%$, $23.1 \%$ and $23.1 \%$ respectively).

Figure1 illustrates that $74 \%$ were VIA negative and $26.0 \%$ were VIA positive.

Table 4 describes the action plan followed by the researcher for VIA negative cases. Medical diagnosis was confirmed by the on duty physician. Thus more than two fifths were exposed to cervicitis $(41.9 \%)$. Cervical ectropion, polyp and vaginitis were encountered by the rest of cases $(27.9 \%, 13.5 \%$ and $17.6 \%$ respectively). The researcher counseled and accompanied women for treatment which was referral for cauterization, conization or cryosurgery in more than half of the cases $(51.4 \%)$.

Table 5 shows that 17 cases were confirmed to have cervical cancer and referred to oncology unit for staging and proper management. Meanwhile, 41.2\% were treated with surgery together with radiotherapy and chemotherapy.

Table 6 shows that there was statistically significant difference between VIA results and age $>40+$, early marriage $<20$ years, family history of cancer and repeated cervical lacerations.

The most complaints were excessive vaginal discharge, itching, and post coital bleeding.

Table 7 represents that sensitivity and specificity of VIA were found to be $100 \%$ and $89.16 \%$ respectively. The positive predictive value of VIA was $65.38 \%$, while the negative predictive value was $100 \%$ and the accuracy of VIA was $91 \%$.

\section{Discussion:}

Cervical cancer is one of the most prevalent malignant neoplasm among women in developing countries. It is preceded by a long premalignant phase known as cervical intraepithelial neoplasia (CIN) (Mahmoobeh et al., 2007). To detect (CIN 2-3), which are considered to be true precancerous lesions, we need a well implemented secondary prevention system that provides screening for all women at risk as well as treatment of detected abnormalities according to local policy (Sangwa and Salaheddin, 2006) ${ }^{(10)}$. VIA, a relatively cheaper alternative with locally-available equipment can also provide immediate results thereby ensuring an adoption of a "see and treat" approach. Screening or diagnosis of early stage disease and accurate staging are essential for appropriate and timely treatment so that deaths are prevented and quality life is possible. Close to $80 \%$ of invasive cancer cases occur in developing countries, where either there are no screening programs or the programs are 
poorly developed and inefficient. Early treatment prevents up to $80 \%$ of cervical cancers in these countries (Chabra, 2016) ${ }^{(11)}$.

Therefore, the present study was carried out to assess cervical cancer screening for high risk women using acetic acid and implement the plan of nursing action. The study was conducted using a cross-sectional design; the sample was recruited from high risk women attending the Gynecological (OPD) at Zagazig University Hospitals.

According to the present study, the majority of the women were in the age group of 30 years and more with a mean age of 38.9 years. This result was in agreement with Agarwal et al.,(2016) (12) study titled "Visual inspection with acetic acid for cervical cancer screening in a tertiary health care". They reported that their study sample had a mean age of 38.6 years. In the same line, Goyal et al., (2014) $^{(13)}$ study in Ludhiana, Punjab, India about "the role of VIA in cervical cancer screening" found that, the mean age of women presenting to the OPD was 39.4 years. Recently, Abiodun et al., $\mathbf{( 2 0 1 7}^{(14)}$,study in Nigeria which "Assess Comparative efficacy of visual inspection with acetic acid versus cytology for cervical cancer screening" reported that, the mean age of the participants was 42.1years and the majority of the subjects (43.4\%) were between 40 to 49 years.

This is in disagreement with Pourasad-Shahrak et al., study (2015) ${ }^{(15)}$ in Alzahra, Therapeutic Educational Centre, Tabriz, Iran about "comparing the results of Pap smear and Direct Visual Inspection (DVI) with 5\% acetic acid in cervical cancer screening". They found that their study sample had a lower mean age of $33 \pm 7$ years. Also Shaheen, etal, (2014) ${ }^{(16)}$ in India reported that, mean age was 34.5years. In Egypt, Saleh study (2014) (6) titled "can visual inspection with acetic acid be used as an alternative to Pap smear in screening cervical cancer?" found that the mean age of the subjects was 36.2. Such dissimilarities could be attributed to the difference in sample size, the criteria of its and the design used in the research.

As regards age of marriage, our findings revealed that about two thirds of women were married at the age of 20-25 years. This is in accordance with Goyal et al., (2014) ${ }^{(13)}$ who reported that the mean age of first coitus was 20.7 years. Meanwhile, the study conducted by Ibrahim (2013) ${ }^{(17)}$ in Sudan revealed that the mean age of sexual initiation was 20.1. Moreover, the mean age of it in the study of Abiodun et al., (2017) (14) was 23.4years. Conversely, Desire et al., study (2016) (18) in Congo about "Visual inspection with acetic acid and Lugol's iodine in cervical cancer screening" reported that the average age for first sexual intercourse was 17.5 years. The difference was related to the cultural background of each area.

In terms of parity, our result revealed that the majority of women were multigravida and multipara and one fifth of them had their age at first birth below 20 years. This is supported by the finding of Agarwal et al., (2016) ${ }^{(12)}$ who found that $13.8 \%$ of the women were nulliparous, $45.6 \%$ had one or two live births, $28.6 \%$ had three or four, and $12.0 \%$ had five or more. The same finding is also in line with Desire et al., (2016) ${ }^{(18)}$ who found that $86.0 \%$ of cases were multiparous. Similarly, Abiodun et al., (2017) ${ }^{(14)}$ noticed that about one fifth of the respondents (19.8\%) were grandmultiparous. On the contrary, Ibrahim (2013) ${ }^{(17)}$ found that $32.2 \%$ of the women were nulliparous and $64.8 \%$ were parous and the risk of positive VIA was significantly higher among parous than among nulliparous women. This is based on the fact that multiparous women are 
CERVICAL CANCER SCREENING USING ACETIC etc...

more likely subjected to genital tract injuries or infection.

It was interesting to find in the present result that all of the high risk women had normal vaginal deliveries and episiotomy was done for more than two thirds of them but a sizable number were exposed to repeated cervical lacerations. This is partially in agreement with that of Ibrahim $\mathbf{( 2 0 1 3 )}^{(17)}$ who noticed that number of deliveries ranged from one to seven live births with mean of about two births for the study sample and more than three fourths $(76.0 \%)$ of women were episiotomies during vaginal delivery. One explanation is that these women might have unprotected intercourse to get pregnant, so they may have had more exposure to HPV. It may also provide a logic and precise rationale in relation to the positive effects of hormonal changes during pregnancy as possibly making women more susceptible to HPV infection or cancer growth. Another thought is that pregnant women might have weaker immune systems, allowing for HPV infection and cancer growth.

Data pertaining to the present gynecological complaints illustrates that, more than half of women were complaining from excessive vaginal discharge with offensive odor in more than two thirds of them. Moreover, one fifth of the studied women complained of postcoital bleeding. This finding was in agreement with Saleh, (2014) (6) who reported that, the most common presenting symptom was vaginal discharge $(80 \%)$ and the most common finding on speculum examination was chronic cervicitis (38\%). Sherigar et al., study (2010) (19) about "Cervical Cancer Screening by Visual Inspection with Acetic Acid- Interobserver Variability between Nurse and Physician" reported that the common presenting complaint was persistent white discharge per vaginum seen in $64.2 \%$ followed by suspicious looking cervix in $21.4 \%, \&$ post-coital bleeding in 5.6\%.

In this respect Goyal et al., (2014) ${ }^{(13)}$ mentioned that, on analyzing the relationship of presenting complaints with VIA results, $26.3 \%$ women presenting with vaginal discharge were VIA positive. The most significant finding was seen in patients presenting with post-coital bleeding where $61.9 \%$ were VIA positive. In women with cervical erosion, the incidence of positive VIA was $24.2 \%$ which was almost similar to that found in hypertrophied/chronic cervicitis $26.1 \%$. $50 \%$ patients with firm cervix \& $44.44 \%$ patients whose cervix bled on touch were VIA positive.

The present results revealed that three fourths of the subjects had no acetowhite area on the cervix, while more than one fourths of them showed distinct, welldefined, dense acetowhite area close to the squamocolumnar junction. This is compatible with the previous studies of Shaheen, et al., (2014) ${ }^{(16)}$ who reported that VIA was positive in $29.3 \%$, and Goyal et al., (2014) (13) who concluded that $23.7 \%$ were VIA positive. Meanwhile, Ibrahim (2013) ${ }^{(17)}$ revealed that $16.0 \%$ of the screened women had VIA positive test result. Saleh study (2014) (6) co-inside with those of the present study with little variation, where VIA was positive in $12.0 \%$ and $88 \%$ were VIA negative.

Conversely, Abiodun et al., (2017) ${ }^{(14)}$ noticed that positive result was $1.3 \%$ for VIA. In addition, Abdel-Maksoud study (2014) (20) titled "screening for Cervical Cancer among Rural Women Using Visual Inspection with Acetic acid the study was conducted in Family Planning Clinics at El-Shohada Hospital and Salmoon Kably Health Unit at Menoufiya Governorate, Egypt" showed that 13 cases $(1.1 \%)$ from 1150 had positive VIA test. Also, Ibrahim (2013) ${ }^{(17)}$ found that the results of all screened women revealed that $7.6 \%$ was positive with VIA test. The 
discrepancies between the aforementioned results and the present one might be attributed to the criteria of selection of the sample where all women at risk for cervical cancer were recruited for the present study especially those having genital tract infection. On the other hand, the other studies selected asymptomatic women for their sample that is why the incidence of positive VIA test result was lower than that of the present result.

HPV is the central etiologic factor for cervical cancer, and prior studies suggested $\mathrm{C}$. trachomatis may act as an HPV cofactor. It is highly prevalent among sexually active young women and can infect the cervix for long periods of time. C. trachomatis often causes cervicitis. Such inflammation may predispose women to other STDs, including genital HPV infection, by damaging epithelial integrity. Recent studies suggested that a history of $\mathrm{C}$. trachomatis infection was associated with persistence of oncogenic HPV infections, Silins etal. (2005) ${ }^{(21)}$ in their study titled "Chlamydia trachomatis infection and persistence of human papillomavirus" have shown that persistent HPV infections are necessary for progression to highgrade CIN and carcinoma. This corresponds well with the finding of the present study that there was significant relation between the presence of sexually transmitted diseases including chlamydia and positive VIA test result.

In this respect Silins et al., (2005) (21) speculate that the inflammatory response and metaplasia triggered by $\mathrm{C}$. trachomatis infection may encourage cell turnover. Further, persistent C. trachomatis infections may create an inflammatory environment conducive to HPV-induced carcinogenesis by increasing the chance of DNA replication errors that have lead to persistent disease and accumulation of genetically damaged cells. In the same line, Gopalkrishna et al., (2017) ${ }^{(22)}$ observation of a slightly higher rate of Chlamydia infection in cancer cases when compared with that of controls or precancers indicates that $\mathrm{C}$. trachomatis may play a role as a cofactor with regard to the pathological aggressiveness of the disease.

VIA has been more widely investigated for its performance characteristics in detecting cervical neoplasia. The current study finding revealed that sensitivity and specificity of VIA were found to be $100 \%$ and $89.2 \%$ respectively. The positive predictive value of VIA was almost two thirds, while the negative predictive value of VIA reached hundred percent. As for the accuracy of the VIA test it was $91 \%$ which means that VIA test was more accurate.

Similar finding was reported by Saraogi and Gupta study (2014) ${ }^{(23)}$ titled "comparative study of visual inspection of the cervix by $3 \%$ acetic acid (VIA) versus Pap smear by Bethesda method in sexually active women aged 25-50 years as an equally or more effective cervical cancer screening method in a low resource setup". They noticed that, the sensitivity and specificity of VIA was $100 \%$ and $47.8 \%$, respectively. The positive predictive value of VIA was $42.9 \%$ and the negative predictive value was $100.0 \%$ with a diagnostic accuracy of $62.5 \%$.

Saleh (2014) (6) reported that the sensitivity of VIA was $90.0 \%$, the specificity was $37.0 \%$, the positive predictive value was $52.0 \%$ and the negative predictive value was $81.0 \%$. Additionally Shaheen, et al., (2014) (16) mentioned that the sensitivity of VIA is $74.2 \%$ and the specificity of VIA $50.0 \%$. Goyal et al., (2014) ${ }^{(13)}$ reported that the sensitivity of VIA was $86.0 \%$ and specificity $40.5 \%$.

Abdella, study (2014) (24)in the outpatient clinics at Tokh Central Hospital at Qalyubia governorate, Egypt about "Correlation between the degree of 
CERVICAL CANCER SCREENING USING ACETIC etc ...

acetowhite epithelium during visual inspection after acetic acid (via) and the cervical pathology noticed that, VIA test showed a sensitivity of $94.0 \%$, specificity of $44.0 \%$, PPV of $81.0 \%$, and NPV of $75.0 \%$. Shaheen, etal. (2014) ${ }^{(16)}$ reported that VIA specificity was low, as noted in the outcomes of comparing VIA with Papanicolaou test results, perhaps in part because inflammatory lesions become aceto-white. Also, several other variables affect the performance of VIA as the light source, which should be white and condensed and the training and experience of the observer.

Recently Sokkary study (2017) (25) was conducted in Shatby Maternity University Hospital, Alexandria about, "Comparison between Pap smear and visual inspection with acetic acid in screening of premalignant cervical intraepithelial lesion and subclinical early cancer cervix. It revealed that the sensitivity of VIA was $66.7 \%$, the specificity was $91.0 \%$, the positive predictive value was $46.1 \%$, the negative predictive value was $95.9 \%$ and the accuracy was $88.5 \%$. Moreover, Abiodun et al., (2017) (14) concluded that the sensitivity of VIA was $7.7 \%$ with PPV of $25.0 \%$ while specificity was $99.0 \%$ with a NPV of $96.2 \%$.

The reasons behind the VIA specificity being high or low in different researches could be the personnel completing the VIA assessment, clinical criteria not properly used, differences between the research populations, and women with inflammatory conditions included in some but not all of the studies. It also could be due to; the presence of infection and inflammation that take up acetowhite stain, some faint acetowhite areas might have been interpreted as being positive and scoring those areas with distinct acetowhite uptake on cervix as positive.
The overall findings indicate that VIA is useful for screening of cervical cancer in primary health care settings in the study area; however, positive results need to be confirmed by colposcopy and biopsy. It also showed that VIA is a feasible and acceptable cervical cancer screening method in a primary health care setting. VIA test offers hope for universal screening as an alternate method for low resource setting. This finding strongly supports the study research hypothesis that VIA can effectively identify more cases of cervical intraepithelial neoplasia.

\section{Conclusion:}

High risk women were more likely to be in the age group of 30 years and more, had secondary level of education, housewives and rural dwellers. Two thirds of them were married at the age of 20-25 years and almost one fifth had family history of cancer. Almost one third of them had irregular cycle and complained of inter-menstrual bleeding. They also had high parity, more episiotomies and vaginal lacerations. Some women were exposed to STD, chlamydia was the most common followed by an equal percentage of genital herpes and warts.

Gynecological signs and symptoms were reported by the majority of the sample include; abnormal vaginal discharge, post coital bleeding and signs of genital tract infection. More than one fourth of the sample had positive VIA test with higher percent of sensitivity, specifity and accuracy. Finally, the researcher plan and implement the action that should be taken in terms of counseling, referral for further screening and treatment as well as follow up for women with positive and negative VIA test.

\section{Recommendations:}

- VIA should be actively advocated to improve detection rate of cervical lesions so that it should be performed in all the women 
attending outpatient gynecological clinics.

- Training programs should be proposed for maternity nurses to update their knowledge about the screening and management of the precancerous lesion of cancer cervix.

Women should be warned against the complications of STD, HPV, chlamydia and their recurrence. Patients should complete their treatment together with their husbands and the standard schedule for further screening and check-up should be followed.

Table 1: Distribution of the studied women according to their Sociodemographic characteristics $(\mathrm{n}=100)$ :

\begin{tabular}{|c|c|c|}
\hline $\begin{array}{l}\text { Socio-demographic } \\
\text { characteristics }\end{array}$ & No. & $\%$ \\
\hline \multicolumn{3}{|l|}{ Age (years) } \\
\hline$<30$ & 17 & 17.0 \\
\hline$>30$ & 83 & 83.0 \\
\hline Mean \pm SD & $38.9 \pm 7.3$ & \\
\hline \multicolumn{3}{|l|}{ Educational level } \\
\hline - $\quad$ Illiterate & 21 & 21.0 \\
\hline - $\quad$ Read / write & 10 & 10.0 \\
\hline $\begin{array}{l}\text { Primary/ } \\
\text { Preparatory }\end{array}$ & 29 & 29.0 \\
\hline - $\quad$ Secondary & 30 & 30.0 \\
\hline - University & 10 & 10.0 \\
\hline \multicolumn{3}{|l|}{ Occupation } \\
\hline - $\quad$ Housewife & 61 & 61.0 \\
\hline - $\quad$ Working & 39 & 39.0 \\
\hline \multicolumn{3}{|l|}{ Residence } \\
\hline - Urban & 31 & 31.0 \\
\hline - $\quad$ Rural & 69 & 69.0 \\
\hline \multicolumn{3}{|l|}{ Smoking } \\
\hline -Passive smoker & 30 & 30.0 \\
\hline \multicolumn{3}{|l|}{$\begin{array}{l}\text { - Mean } \pm \text { SD Duration of } \\
\text { exposure }\end{array}$} \\
\hline & $14.4 \pm 7.3$ & \\
\hline
\end{tabular}

Table 2: Distribution of the studied women according to the characteristics of their marriage $(\mathrm{n}=100)$ :

\begin{tabular}{|c|c|c|}
\hline Variables & No. & $\%$ \\
\hline \multicolumn{3}{|l|}{ Marital status } \\
\hline - $\quad$ Married & 70 & 70.0 \\
\hline - Widow & 23 & 23.0 \\
\hline - $\quad$ Separated & 7 & 7.0 \\
\hline \multicolumn{3}{|l|}{ Age at Marriage } \\
\hline - $\quad<20$ & 28 & 28.0 \\
\hline - $20-25$ & 59 & 59.0 \\
\hline - $>25$ & 13 & 13.0 \\
\hline Mean \pm SD & $21.5 \pm 2.9$ & \\
\hline \multicolumn{3}{|l|}{ Duration of marriage } \\
\hline - $1-5$ years & 9 & 9.0 \\
\hline - $6-15$ years & 15 & 15.0 \\
\hline - $\quad>16$ years & 76 & 76.0 \\
\hline \multicolumn{3}{|l|}{ Number of marriages } \\
\hline - $\quad$ One marriage & 92 & 92.0 \\
\hline $\begin{array}{ll} & \text { Two } \\
\text { marriages }\end{array}$ & 8 & 8.0 \\
\hline
\end{tabular}

Table 3: Distribution of the studied women according to history of STD exposure $(n=100)$ :

\begin{tabular}{|c|c|c|}
\hline Exposure to STD & No. & $\%$ \\
\hline - $\quad$ No & 87 & 87.0 \\
\hline Yes & 13 & 13.0 \\
\hline \multicolumn{3}{|l|}{ Type of STD $(n=13)$} \\
\hline - $\quad$ Chlamydia & 7 & 53.8 \\
\hline - Genital herpes & 3 & 23.1 \\
\hline - $\quad$ Genital warts & 3 & 23.1 \\
\hline
\end{tabular}

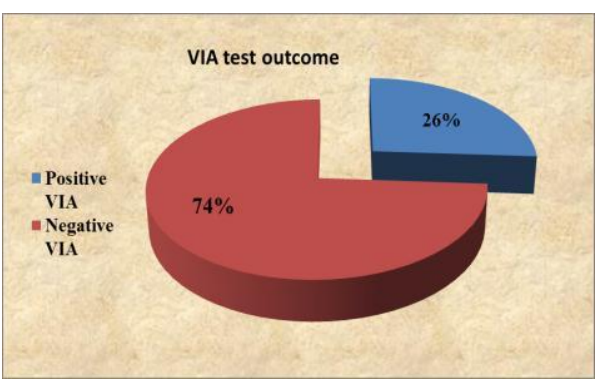

Figure 1: Distribution of the studied women according to VIA test outcome $(n=100)$ : 
CERVICAL CANCER SCREENING USING ACETIC etc ...

\begin{tabular}{|c|c|c|}
\hline \multicolumn{3}{|c|}{$\begin{array}{l}\text { Table (4): Distribution of the studied } \\
\text { women according to the follow up of } \\
\text { the VIA negative cases }(n=74) \text { : }\end{array}$} \\
\hline \begin{tabular}{|l|} 
Variables \\
\end{tabular} & No. & $\%$ \\
\hline \multicolumn{3}{|l|}{ Diagnosis } \\
\hline - $\quad$ Cervicitis & 31 & 41.9 \\
\hline - $\quad$ Cervical Polyp & 10 & 13.5 \\
\hline $\begin{array}{ll}\text { Cervical } \\
\text { ectropion }\end{array}$ & 20 & 27.0 \\
\hline - Vaginitis & 13 & 17.6 \\
\hline \multicolumn{3}{|l|}{ The undertaken action } \\
\hline $\begin{array}{l}\text { - Medical treatment } \\
\text { for infection and } \\
\text { return after 2weeks } \\
\text { Referral for } \\
\text { cauterization, } \\
\text { conization or or } \\
\text { cryosurgery }\end{array}$ & $\begin{array}{l}26 \\
38\end{array}$ & $\begin{array}{l}35.1 \\
51.4\end{array}$ \\
\hline $\begin{array}{l}\text { Referral for surgical } \\
\text { removal of polyp }\end{array}$ & 10 & 13.5 \\
\hline
\end{tabular}

\begin{tabular}{|c|c|c|}
\hline Variables & No. & $\%$ \\
\hline \multicolumn{3}{|l|}{ The action taken } \\
\hline - $\quad$ Cervical Biopsy & 20 & 76.9 \\
\hline - Colposcopy & 6 & 23.1 \\
\hline \multicolumn{3}{|l|}{$\begin{array}{l}\text { The results of suspected } \\
\text { VIA positive cases }\end{array}$} \\
\hline $\begin{array}{l}\text { - } \begin{array}{l}\text { Cancer not } \\
\text { confirmed }\end{array} \\
\text { cons }\end{array}$ & 9 & 34.6 \\
\hline $\begin{array}{l}\text { Cancer } \\
\text { confirmed and } \\
\text { referred to } \\
\text { oncology unit } \\
\text { for staging }\end{array}$ & 17 & 65.4 \\
\hline \multicolumn{3}{|l|}{$\begin{array}{l}\text { Treatment of confirmed } \\
\text { cases }(n=17)\end{array}$} \\
\hline - $\quad$ Surgery alone & 3 & 17.6 \\
\hline $\begin{array}{l}\text { - } \begin{array}{c}\text { Surgery with } \\
\text { radiotherapy }\end{array} \\
\end{array}$ & 4 & 23.6 \\
\hline $\begin{array}{l}\text { Surgery with } \\
\text { chemotherapy }\end{array}$ & 3 & 17.6 \\
\hline $\begin{array}{l}\text { - Surgery with } \\
\text { radiotherapy and } \\
\text { chemotherapy }\end{array}$ & 7 & 41.2 \\
\hline
\end{tabular}

Table 6: The relation between the risk factors and the VIA test results

\begin{tabular}{|c|c|c|c|c|c|c|}
\hline \multirow[b]{2}{*}{ Variables } & \multicolumn{2}{|c|}{$\begin{array}{c}\text { Negative } \\
\text { VIA }(n=74)\end{array}$} & \multicolumn{2}{|c|}{$\begin{array}{c}\text { Positive VIA } \\
(n=26)\end{array}$} & \multicolumn{2}{|c|}{ Chi square test } \\
\hline & No. & $\%$ & No. & $\%$ & $\mathbf{X}^{2}$ & $\mathbf{p}$ \\
\hline Age (years) $>40$ & 18 & 24.3 & 25 & 96.2 & 40.540 & $<0.001 *$ \\
\hline Age at Marriage $<20$ years & 11 & 14.9 & 17 & 65.4 & 24.426 & $<0.001 *$ \\
\hline Family $\mathrm{H}$ of cancer & 1 & 1.4 & 16 & 61.5 & 49.956 & $<0.001 *$ \\
\hline vaginal deliveries $>5$ or more & 4 & 5.7 & 12 & 48.0 & 26.019 & $<0.001 *$ \\
\hline Repeated cervical Laceration & 8 & 11.4 & 20 & 80.0 & 41.669 & $<0.001 *$ \\
\hline Excessive vaginal discharge & 29 & 39.2 & 24 & 92.3 & 21.793 & $<0.001 *$ \\
\hline External anogenital itching & 9 & 12.2 & 22 & 84.6 & 47.218 & $<0.001 *$ \\
\hline Post-coital bleeding & 8 & 10.8 & 9 & 34.6 & 7.727 & $0.005^{*}$ \\
\hline
\end{tabular}

Table 7: Sensitivity, Specificity, positive predictive value, negative predictive value and accuracy of VIA screening test $(n=100)$ :

\begin{tabular}{|l|c|l|l|}
\hline & & \multicolumn{1}{|c|}{$95 \%$ CI } & \\
\hline Item & Value & Lower & Upper \\
\hline Sensitivity & $100 \%$ & $80.49 \%$ & $100 \%$ \\
\hline Specificity & $89.16 \%$ & $80.41 \%$ & $94.92 \%$ \\
\hline Positive predictive value & $65.38 \%$ & $50.48 \%$ & $77.78 \%$ \\
\hline Negative predictive value & $100 \%$ & $97.49 \%$ & $100 \%$ \\
\hline Accuracy & $91 \%$ & $83.60 \%$ & $95.80 \%$ \\
\hline
\end{tabular}




\section{References:}

1. Ferlay, J., Soerjomataram, I, Ervik, M, Dikshit, R, Eser, S, Mathers, C, et al., (2012). GLOBOCAN 2012 v1.0, Cancer Incidence and Mortality Worldwide: IARC Cancer Base No.

11. Lyon, France: International Agency for Research on Cancer; 2013.

2. World Health Organization Information Centre on HPV and Cancer. Human papillomavirus and related cancers in Egypt. Summary report. WHO/ICO; 2010. Available at: http://www.hpvcentre.net/statistics/re ports/EGY.pdf (accessed January 9, 2014).

3. American Cancer Society (2012). American Society for Colposcopy and Cervical Pathology, and American Society for Clinical Pathology screening guidelines for the prevention and early detection of cervical cancer.J Low Genit Tract Dis, 16, 3,175-204.

4. World Health Organization (2013). WHO guidelines for screening and treatment of precancerous lesions for cervical cancer prevention. Geneva, Switzerland:

5. Fong, J, Gyaneshwar, R, Lin, S, Morrell, S, Taylor, R, and Catherine, M (2014). Cervical Screening Using Visual Inspection with Acetic Acid (VIA) and Treatment with Cryotherapy in Fiji Asian Pacific Journal of Cancer Prevention;15:10757-10762.

6. Saleh, H.S, (2014). Can visual inspection with acetic acid be used as an alternative to Pap smear in screening cervical cancer? Middle East Fertility Society Journal; 19: 187-191.

7. Longatto-Filho, A, Naud, P, Derchain, SF, Roteli-Martins, C, Tatti, S, Hammes, LS, et al(2012).
Performance characteristics of Pap test, VIA, VILI, HR-HPV testing, cervicography, and colposcopy in diagnosis of significant cervical pathology. Virchows Arch; 460:577585.

8. World Health Organization (2012). Enhancing nursing and midwifery capacity to contribute to the prevention, treatment and management of noncommunicable diseasesGeneva, Switzerland / November 2012 Issue no12Human Resources for Health Observer, 12).

9. Donnelly, E, Refaat, T Gentile, M, et.al., (2015). Evaluation of Outcomes in Patients With Carcinoma of the Cervix Treated With Concurrent Radiation and Cisplatin Versus Cisplatin/5-FU Compared With Radiation Alone. American Journal of Clinical Oncology, 38, 5, 437-441.

10. Sangwa, LG and Salaheddin, M (2006). Visual inspection as a cervical cancer screening method in a primary health care setting in Africa. International Journal of Cancer; 119: 1389-1395.

11. Chhabra, S (2016). Early Stage Cervical Cancer, Therapy for Reproductive Health and Quality Survival. Open Med Journal, 1, 3, 111.

12. Agarwal, S, Gupta, R, Agarwal, A, Pandey, K, Gupta, N and Katiyar, A(2016). Visual inspection with acetic acid for cervical cancer screening in a tertiary health care centre. Int J Reprod Contracept Obstet Gynecol, 5, 3,752-756.

13. Goyal, S, Tandon, P, Bhutani, N and GillB, K (2014). To study the role of visual inspection of cervix with acetic acid (VIA) in cervical cancer screening Int J Reprod Contracept Obstet Gynecol;3: 684 -687. 
CERVICAL CANCER SCREENING USING ACETIC etc ...

14. Abiodun, AB, Durodola, AO, Ajani, MA, Amole, IO, Abiodun, AD, Oluwasola, TAO(2017). Comparative efficacy of visual inspection with acetic acid versus cytology for cervical cancer screening in Ogbomoso, Nigeria. Int J Reprod Contracept Obstet Gynecol, 6,9,37423747.

15. Pourasad-Shahrak, S, SalehiPourmehr H, Mostafa-Garebaghi, P, Asghari-Jafarabadi, M, Malakouti, J and Haghsay ,M (2015). Comparing the results of Pap smear and Direct Visual Inspection (DVI) with 5\% acetic acid in cervical cancer screening. Niger Med J, 56, 1, 35-38.

16. Shaheen, Sharma, $\mathrm{R}$ and Rash,i(2014).Visual Inspection with Acetic Acid (VIA) in cervical cancer screening in low resource settings Bangladesh Journal of Medical Science, 13 , 4, 454-459.

17. Ibrahim, A (2013).Cervical Cancer, Risk Factors and Feasibility of Visual Inspection with Acetic Acid Screening Method in Khartoum State, Sudan, International Journal of Women's Health; 3:117-122.

18. Desire, BK, Philippe, CM, \& Thierry, $\mathrm{K}$, et al., (2016). Visual inspection with acetic acid and Lugol's iodine in cervical cancer screening at the general referral hospital Kayembe in Mbuji-Mayi, Democratic Republic of Congo. Pan African Medical Journal, 23, 64, 1-8.

19. Sherigar, B, Dalal, A, Durdi, G, Pujar, $Y$ and Dhumale, H (2010). Cervical Cancer Screening by Visual Inspection with Acetic AcidInterobserver Variability between Nurse and Physician. Asian Pacific J Cancer Prev, 11, 619-622.

20. Abdel-Maksoud, N (2014). Screening for Cervical Cancer among Rural Women Using Visual Inspection with Acetic acid. Thesis (M.S.)-Menoufia
University. Faculty of Nursing. Department of Community Health Nursing.

21. Silins, I, Ryd, W, Strand, A, Wadell, G, Tornberg, S, Hansson, BG, et al (2005). Chlamydia trachomatis infection and persistence of human papillomavirus. Int $\mathrm{J}$ Cancer; 116:110-115.

22. Gopalkrishna, V, Aggarwal, N, Malhotra, VL, Koranne, RV, etal., ( 2017). Chlamydia trachomatis and human papillomavirus infection in Indian women with sexually transmitted diseases and cervical precancerous and cancerous lesions, 1469-0691.accessed at november 2017.

23. Saraogi, MR and Gupta, A (2014). Comparative study of visual inspection of the cervix by $3 \%$ acetic acid (VIA) versus Pap smear by Bethesda method in sexually active women aged 25-50 years as an equally or more effective cervical cancer screening method in a low resource setup. Int $\mathbf{J}$ Reprod Contracept Obstet Gynecol; 3:688691.

24. Abdella, H (2014). Correlation between the degree of acetowhite epithelium during visual inspection after acetic acid (via) and the cervical pathology. Thesis (M.S) - Banha University. Faculty of medicine. Department of obstetrics and gynecology.

25. Sokkary, HH (2017). Comparison between Pap smear and visual inspection with acetic acid in screening of premalignant cervical intraepithelial lesion and subclinical early cancer cervix. Int $\mathbf{J}$ Reprod Contracept Obstet Gynecol; 6:54-59. 